\title{
A PROSPECTIVE STUDY OF THE CLINICAL PROFILE AND OUTCOMES OF HYPERTENSIVE DISORDERS OF PREGNANCY (HDSP) ADMITTED TO A MULTIDISCIPLINARY ICU
}

\author{
Baby Sailaja K1, Renuka M. $K^{2}$
}

${ }_{1}^{1}$ Assistant Professor, Department of Critical Care Medicine, Sri Ramachandra Medial College and Research Institute, Chennai, Tamilnadu, India.

2Professor, Department of Anaesthesiology, Sri Ramachandra Medial College and Research Institute, Chennai, Tamilnadu, India.

\section{ABSTRACT}

\section{BACKGROUND}

Hypertensive disorders of pregnancy (HDsP) are associated with significant mortality and morbidity of the pregnant patient with wide variations between developed and developing countries. In the present study, we aim to evaluate the magnitude, complications, mortality, and morbidity of patients with HDsP who were admitted to a multidisciplinary intensive care unit (ICU) of a tertiary hospital.

\section{METHODS}

We conducted a prospective observational study for two years on all obstetric patients with HDsP shifted to the multidisciplinary ICU of a tertiary care hospital. Demographic profile prevalence of various hypertensive disorders, associated complications, interventions and outcomes were analysed.

\section{RESULTS}

Forty-one patients were admitted to the ICU with hypertension complicating pregnancy and carried an ICU mortality rate of $7.3 \%$ $(n=3)$. The mean age of the study group was $31.22 \pm 6.5$ years. Majority of them were primigravidae (59\%), in their third trimester $(53.7 \%)$ and received antenatal care $(85.3 \%)$. Preeclampsia $(n=19)$ and eclampsia $(n=13)$ accounted for $79 \%$ of admission to ICU. Most of them were shifted to ICU during the postpartum period (93\%) and 58.6\% underwent caesarean section. Haemolysis, Elevated Liver Enzymes, and Low Platelet syndrome (19.5\%), Posterior Reversible Encephalopathy syndrome (31.7\%) and acute renal failure $(22 \%)$ were common among the complications. Sequential Organ Failure Assessment score (SOFA) were significantly high among the non survivors indicating multiple organ system involvement.

\section{CONCLUSIONS}

Hypertensive disorders of pregnancy remain the most common cause of admission to ICU among the critically ill obstetric patie nts causing significant mortality and morbidity.

\section{KEY WORDS}

Eclampsia, preeclampsia, Intensive care unit, hypertensive disorders of pregnancy, PRES

HOW TO CITE THIS ARTICLE: Sailaja BK, Renuka MK. A prospective study of the clinical profile and outcomes of hypertensive disorders of pregnancy (HDsP) admitted to a multidisciplinary ICU. J. Evolution Med. Dent. Sci. 2019;8(26):2037-2040, DOI: $10.14260 /$ jemds $/ 2019 / 449$

\section{BACKGROUND}

Hypertensive disorders of pregnancy (HDsP) are common clinical condition occurring in pregnant patients and are usually associated with a successful pregnancy. It manifests during antenatal or intrapartum period, but postpartum presentation is not unusual. They are supposed to be the cause for maternal mortality in about 14\% pregnancies globally.(1) Women at advanced maternal age (Above 35 yrs.), primiparity, multifetal pregnancy, previous history of preeclampsia, underlying chronic hypertension, diabetes, renal disease can pose a risk for the development of hypertension during pregnancy. The most common HDP is

'Financial or Other Competing Interest': None.

Submission 09-03-2019, Peer Review 29-03-2019,

Acceptance 01-04-2019, Published 01-07-2019.

Corresponding Author:

Dr. Renuka M. K,

Professor, Department of Anaesthesiology,

Sri Ramachandra Medical College and

Research Institute, Chennai,

Tamilnadu, India.

E-mail: renuramanujam@gmail.com

DOI: $10.14260 / j e m d s / 2019 / 449$ preeclampsia-eclampsia. Progression to eclampsia is associated with acute and fatal complications -placental abruption, liver rupture/ hematoma, neurologic complications like stroke and cortical blindness, disseminated intravascular coagulation, acute pulmonary oedema, cardiorespiratory arrest, acute renal failure. The increased maternal mortality and morbidity were secondary to the development and rapid progression of these serious complications among certain patients. Till date there are no specific prognostic indicators to identify the patients who might progress to such complications. Therefore, these patients often require admission to intensive care unit (ICU) for careful monitoring and early identification of the development of complications.

The objective of managing a patient with HDsP is to stabilize the mother and salvage of fetus should be based on the gestational age at the onset of symptoms of severe preeclampsia. The current approach in the management of HDsP is expectant management after ensuring the maternal and fetal wellness. The current recommendations are oral and intravenous antihypertensives for control of blood pressure, magnesium sulphate administration for prevention and control of seizures and delivery of fetus after maternal stabilisation irrespective of fetal viability in severe disease.(2) 
Administration of early appropriate therapy were associated with good outcomes.(3) As there is a dearth of data on the clinical profile of obstetric patients with HDsP admitted to the ICU, we intended to conduct a prospective study on the clinical profile and outcomes of this special population who got admitted to our multidisciplinary ICU.

\section{Aims and Objectives}

The present study was conducted to assess the magnitude of HDsP among obstetric patients admitted to a multidisciplinary ICU, the associated complications, interventions required, in-hospital mortality and morbidity of the obstetric patients with HDsP admitted to our multidisciplinary ICU.

\section{METHODS}

A prospective observational study was conducted for a period of two years on consecutive obstetric patients (pregnant or within six weeks postpartum) with HDsP who required ICU care. Institutional ethics committee approval was obtained to conduct the study. Demographic data pertaining to age, parity, trimester, prenatal care, parturient status at the time of ICU admission, mode of delivery were recorded. Interventions provided in the form of mechanical ventilation, treatment with magnesium sulphate, labetalol, diuretics and transfusion therapy were recorded. Admission day APACHE II (Acute Physiology and Chronic Health Evaluation II)(4) and worst SOFA (Sequential Organ Failure Assessment)(5) scores were calculated to assess the severity of illness of the study group. The in-hospital mortality is the primary outcome measured. Average length of stay (LOS) in the hospital, ICU LOS, ventilator days were the secondary outcomes studied.

Statistical Package for Social Science (SPSS, version 17) for Microsoft windows was used to analyse the data. The data were expressed as mean and standard deviation for continuous variables and percentages and numbers for categorical variables. Further analysis was done by applying Independent samples student $\mathrm{t}$ test/ Mann Whitney test for continuous variables and Chi square test for categorical variables. A $\mathrm{p}$ value $<0.05$ was considered statistically significant.

\section{RESULTS}

During the two-year period, out of the 92 obstetric admissions to ICU, 41 patients (44.56\%) were found to be complicated with hypertension during pregnancy. The mean age of the study group was $31.22 \pm 6.5$ years. About $59 \%$ $(n=24)$ were primigravidae and $53.7 \%(n=22)$ were in their third trimester at the time of admission. Eighty five percent had prenatal care either in our hospital $(n=16)$ or at other facilities $(n=19)$. Almost 93\% $(n=38)$ were shifted to ICU during the postpartum period. (Table 1)

\begin{tabular}{|c|c|c|c|c|}
\hline Variable & Total $(n=41)$ & Survivors $(n=38)$ & Non-Survivors $(n=3)$ & p Value \\
\hline Age(Years), Mean \pm SD & $31.22 \pm 6.5$ & $31.18 \pm 6.4$ & $31.67 \pm 9.0$ & $0.903^{*}$ \\
\hline Parity, n (\%) & & & & 1 \\
\hline$<2$ & $24(58.5)$ & $22(91.7)$ & $2(8.3)$ & \\
\hline$\geq 2$ & $17(41.5)$ & $16(94.1)$ & $1(5.9)$ & \\
\hline Trimester, n (\%) & & & & 0.136 \\
\hline II Trimester & $9(22)$ & $7(77.8)$ & $2(22.2)$ & \\
\hline III Trimester & 22 (53.7) & $21(95.5)$ & $1(4.5)$ & \\
\hline Postpartum & $10(24.4)$ & $10(100)$ & $0(0)$ & \\
\hline Prenatal care, n (\%) & & & & 0.674 \\
\hline Booked & $16(39)$ & $15(93.8)$ & $1(6.3)$ & \\
\hline Unbooked & $6(14.6)$ & $6(100)$ & $0(0)$ & \\
\hline Referred & $19(46.3)$ & $17(89.5)$ & $2(10.5)$ & \\
\hline Parturient status, n (\%) & & & & 0.01 \\
\hline Antepartum & $3(7.3)$ & $1(33.3)$ & $2(66.7)$ & \\
\hline Postpartum & 38 (92.7) & $37(97.4)$ & $1(2.6)$ & \\
\hline
\end{tabular}

Table 1. Demographic Data of Obstetric Patients with Hypertensive Disorders of Pregnancy Admitted to ICU

$\mathrm{SD}=$ Standard deviation; *Independent student $\mathrm{t}$ test

The underlying hypertensive disorder was preeclampsia (58.5\%) in majority of the study population followed by chronic hypertension (24.4\%). (Table 2) At the time of transfer to ICU, nine patients (33\%) with preeclampsia were admitted with eclampsia, seven patients (70\%) with chronic hypertension progressed to preeclampsia and one patient developed eclampsia. Underlying Haemolysis Elevated Liver enzymes and Low Platelet (HELLP) syndrome was observed in 19.5\% ( $\mathrm{n}=8$ ) patients. Seventy seven percent patients admitted with eclampsia to the ICU showed features of posterior reversible encephalopathy syndrome (PRES) on magnetic resonance imaging (MRI).(Figure 1)

\begin{tabular}{|c|c|c|c|}
\hline Diagnosis & Total (n=41) & Survivors (n= 38) & Non-Survivors(n=3) \\
\hline Preeclampsia, n (\%) & $24(58.5)$ & $23(95.8)$ & $1(4.2)$ \\
\hline Chronic Hypertension, n (\%) & $10(24.4)$ & $9(90)$ & $1(10)$ \\
\hline Gestational Hypertension, n (\%) & $3(7.3)$ & $2(66.7)$ & $1(33.3)$ \\
\hline Normotension, n (\%) & $4(9.8)$ & $4(100)$ & $0(0)$ \\
\hline \multicolumn{2}{|r}{} \\
\hline
\end{tabular}




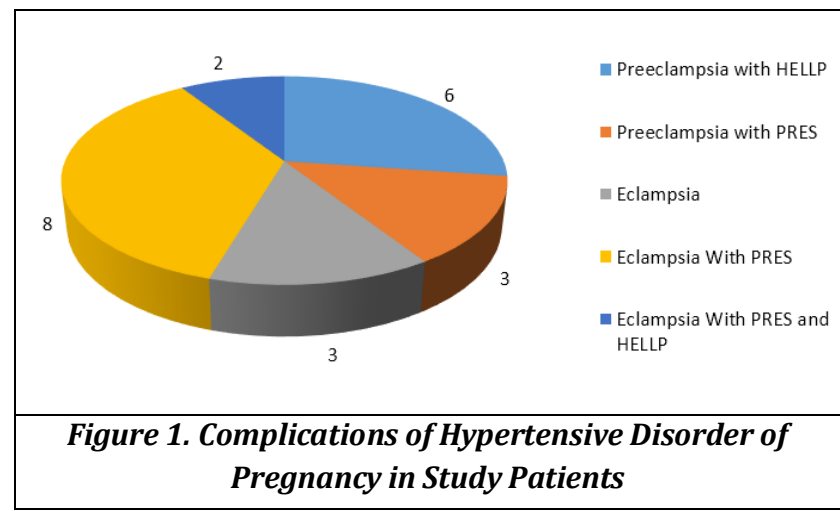

About $60 \%(n=24)$ among the ICU transferred patients underwent caesarean delivery. Invasive ventilation and blood transfusion were given in $56 \%$ patients each. (Table 3 ).

\begin{tabular}{|c|c|}
\hline Intervention & Number (\%) \\
\hline Caesarean Section & $24(58.6)$ \\
\hline Mechanical Ventilation & $23(56.1)$ \\
\hline Magnesium Sulphate Therapy & $15(36.6)$ \\
\hline Labetalol Therapy & $15(36.6)$ \\
\hline Blood Transfusion & $23(56.1)$ \\
\hline Table 3. Interventions Required by The Study Population
\end{tabular}

The worst SOFA score was significantly high among non survivors $(17 \pm 3.60$ vs $5.18 \pm 3.34, p=0.004)$ suggestive of their progression to multi organ failure. The average hospital length of stay (LOS), ICU LOS and ventilator free days did not show any significant difference among survivors and non survivors. (Table 4)

\begin{tabular}{|c|c|c|c|}
\hline Variable & $\begin{array}{c}\text { Survivors } \\
(\mathrm{n}=38)\end{array}$ & $\begin{array}{c}\text { Non-Survivors } \\
(n=3)\end{array}$ & p Value \\
\hline APACHE II, Mean \pm SD & $11.89 \pm 7.92$ & $19.33 \pm 7.23$ & $0.108^{\dagger}$ \\
\hline $\begin{array}{c}\text { Worst SOFA, } \\
\text { Mean } \pm \text { SD }\end{array}$ & $5.18 \pm 3.34$ & $17 \pm 3.60$ & $0.004^{\dagger}$ \\
\hline Hospital LOS (Days) & $8.63 \pm 4.65$ & $10 \pm 6.24$ & $0.58^{\dagger}$ \\
\hline $\begin{array}{l}\text { ICU LOS (Days) } \\
\text { Mean } \pm \text { SD }\end{array}$ & $3.11 \pm 1.68$ & $8.33 \pm 7.02$ & $0.28 \dagger$ \\
\hline $\begin{array}{l}\text { ICU Free Days, } \\
\text { Mean } \pm \text { SD }\end{array}$ & $5.53 \pm 4.07$ & $1.67 \pm 1.52$ & $0.063^{\dagger}$ \\
\hline $\begin{array}{c}\text { Ventilator Days, } \\
\text { Mean } \pm \text { SD }\end{array}$ & $2.2 \pm 2.0$ & $6.50 \pm 5.22$ & $0.265^{\dagger}$ \\
\hline $\begin{array}{l}\text { Ventilator Free Days, } \\
\text { Mean } \pm \text { SD }\end{array}$ & $7.47 \pm 4.63$ & $3.5 \pm 1.32$ & $0.098^{\dagger}$ \\
\hline \multicolumn{4}{|c|}{$\begin{array}{l}\text { Table 4. Severity of IIIness Score and Outcomes of Study } \\
\text { Population }\end{array}$} \\
\hline \multicolumn{4}{|c|}{$\begin{array}{l}\text { APACHE=Acute Physiology and Chronic Health } \\
\text { Evaluation; SOFA= Sequential Organ Failure Assessment; } \\
\text { SD=Standard Deviation; LOS= Length of Stay; ICU=Intensive } \\
\text { Care Unit; †=Mann Whitney Test }\end{array}$} \\
\hline
\end{tabular}

Acute renal failure and acute pulmonary oedema were the complications that occurred more frequently in our study patients. (Figure 2)

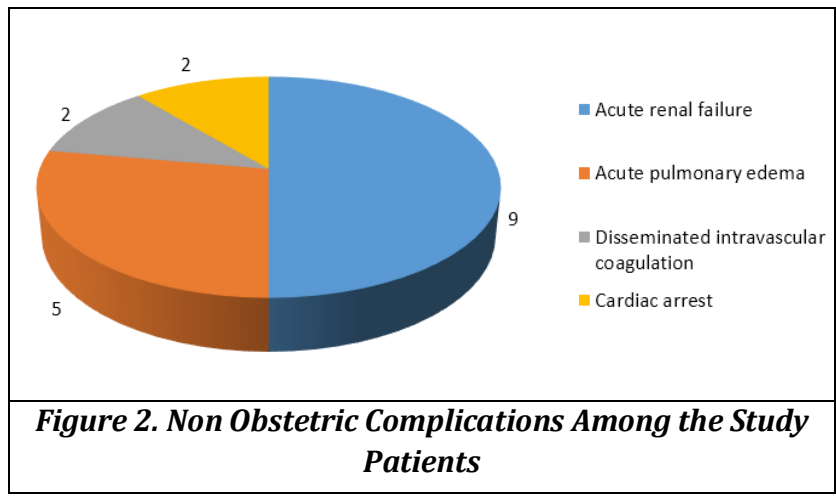

\section{DISCUSSION}

The American College of Obstetricians and Gynaecologists (ACOG) task force ${ }^{(2)}$ categorises HDsP as chronic hypertension, gestational hypertension, preeclampsiaeclampsia and superimposed preeclampsia. The International Society for the Study of Hypertension in Pregnancy (ISSHP) ${ }^{(6)}$ additionally includes white coat hypertension as it increases the risk for preeclampsia.

Hypertension during pregnancy is associated with adverse maternal outcomes in short term as well as long term. ${ }^{7}$ The expected short-term adversities are maternal mortality, caesarean delivery, eclampsia and prolonged hospital stay warranting the management of these critically ill patients in the ICU. They are the leading cause for admission of obstetric patients into ICU and the incidence varied between different countries, $26.83 \%$, (8) $58 \%$, (9) $16.6 \%{ }^{(10)}$ and $62.7 \% .^{(11)}$ In our study we observed a prevalence of $44.56 \%$ and was comparable to the existing data.

Younger or advanced maternal age is a risk factor for development of hypertension during pregnancy. $(7,12)$ The minimum and maximum age observed in our study population was 21 and 44 years respectively with a mean age of 31 years and is comparable with other studies. $(13,14)$ Majority of our patients were in their third trimester at the time of onset of illness, similar to that observed by Curiel Balsera et al(14) and Vasquez et al.(15)

Though adequate prenatal care was sought by $85 \%$ of our study group, the need for emergent ICU care in these patients may suggest the rapidity of deterioration. Vasquez et al also showed a similar prenatal care in their study.(15)

In our study, majority of patients had a caesarean delivery. This may be probably due to the severity of illness at presentation and lack of adequate time for vaginal delivery. A similar caesarean section rate was observed even in other studies. $(10,14)$ High incidence of postpartum admission for monitoring the development of complications as observed in our study was noticed in another study.(15)

At the time of ICU transfer, $46.3 \%(n=19)$ patients had preeclampsia and another $31.7 \%(\mathrm{n}=13)$ patients were complicated by eclampsia $(31.7 \%)$. Of them, eight patients (19.5\%) had underlying HELLP syndrome at ICU admission. A similar prevalence of HDsP was observed in the study by Vasquez et al.(15) Almost $80 \%$ of chronic hypertensives and all patients with gestational hypertension progressed to either preeclampsia or developed complication in the form of eclampsia. A similarly high rate of progression of these disorders to preeclampsia/eclampsia was demonstrated in a pilot trial by Magee et al.(16) 
An unusually high incidence of PRES (31.7\%) was present among the eclamptic patients in our study population. Abalos et al described a high prevalence neurological dysfunction including PRES in his study.(12)

The need for invasive ventilation in our study population was similar to the general critically ill obstetric patients getting admitted to ICU.(17) In the present study population due to the serious illness and development of complications the ICU stay was prolonged. This was longer when compared to the ICU stay of general critically ill obstetric patients admitted to ICU as observed in a systemic review by Pollock et al(17) and from other studies. ${ }^{18,19)}$

HDsP remains the third leading cause of direct obstetric deaths worldwide.(1) The observed maternal mortality among our special population was $7.3 \%(\mathrm{n}=3)$ and all progressed to multiple organ failure at the time of death. The incidence of renal dysfunction in HDsP varied from $5 \%$ to $24 \%$ in various studies. $(10,12,14)$ In our study nine patients $(22 \%)$ had acute kidney injury of which three patients needed renal replacement therapy. Two patients went into cardiac arrest, one following a seizure in the labour ward and the other following acute pulmonary oedema leading to hypoxia during labour. These two patients required tracheostomy due to failed weaning and hypoxic ischemic encephalopathy respectively.

In the current study due to the smaller sample size, no conclusions could be drawn regarding the risk factors for the incidence and development of life-threatening complications. Further studies with large sample size are needed to identify the risk factors and to formulate early interventions to prevent mortality and morbidity in this special population.

\section{CONCLUSIONS}

Hypertension during pregnancy still remains an important cause for admission of obstetric patients to the ICU. The unpredictability of progression and development of lifethreatening complications in the presence of underlying hypertension, mandates all these patients be recognized early, and be followed by a team management in ICU to reduce the mortality and morbidity.

\section{REFERENCES}

[1] Say L, Chou D, Gemmill A, et al. Global causes of maternal death: a WHO systematic analysis. The Lancet Global Health 2014;2(6):e323-e33.

[2] American College of Obstetricians and Gynecologists. Hypertension in pregnancy. Report of the American College of Obstetricians and Gynecologists' Task Force on Hypertension in Pregnancy. Obstetrics and Gynecology 2013;122(5):1122-31.

[3] Pollard SL, Mathai M, Walker N. Estimating the impact of interventions on cause-specific maternal mortality: a Delphi approach. BMC Public Health 2013;13(3):S12.

[4] Knaus WA, Draper EA, Wagner DP, et al. APACHE II: a severity of disease classification system. Critical Care Medicine 1985;13(10):818-29.

[5] Vincent JL, Moreno R, Takala J, et al. The SOFA (Sepsisrelated Organ Failure Assessment) score to describe organ dysfunction/failure. Intensive Care Medicine 1996;22(7):707-10.

[6] Brown MA, Magee LA, Kenny LC, et al. Hypertensive disorders of pregnancy: ISSHP classification, diagnosis, and management recommendations for international practice. Hypertension 2018;72(1):24-43.
[7] Shih T, Peneva D, Xu X, et al. The rising burden of preeclampsia in the United States impacts both maternal and child health. American Journal of Perinatology 2016;33(04):329-38.

[8] Dasgupta S, Jha T, Bagchi P, et al. Critically ill obstetric patients in a general critical care unit: a 5 years' retrospective study in a public teaching hospital of Eastern India. Indian Journal of Critical Care Medicine 2017;21(5):294-302.

[9] Vasquez DN, Das Neves AV, Vidal L, et al. Characteristics, outcomes and predictability of critically ill obstetric patients: a multicenter prospective cohort study. Critical Care Medicine 2015;43(9):1887-97.

[10] Desalegn N, Haile M. Causes of admission and out comes among preeclampsia and eclampsia mothers admitted to Jimma University Specialized Hospital Intensive Care Unit. Clinical Medicine Research 2015;4(5):154-9.

[11] Oliveira LC, da Costa AA. Maternal near miss in the intensive care unit: clinical and epidemiological aspects. Revista Brasileira de Terapia Intensiva 2015;27(3):220-7.

[12] Abalos E, Cuesta C, Carroli G, et al. Pre-eclampsia, eclampsia and adverse maternal and perinatal outcomes: a secondary analysis of the World Health Organization Multicountry Survey on Maternal and Newborn Health. BJOG: An International Journal of Obstetrics \& Gynaecology 2014;121(Suppl 1):14-24.

[13] Das R, Biswas S. Eclapmsia: the major cause of maternal mortality in Eastern India. Ethiopian Journal of Health Sciences 2015;25(2):111-6.

[14] Curiel-Balsera E, Prieto-Palomino MA, Munoz-Bono J, et al. Analysis of maternal morbidity and mortality among patients admitted to Obstetric Intensive Care with severe preeclampsia, eclampsia or HELLP syndrome. Medicina Intensiva (English Edition) 2011;35(8):478-83.

[15] Vasquez DN, Neves AV, Zakalik G, et al. OS024. Characteristics and outcomes of critically ill obstetric patients with hypertensive disease of pregnancy in Argentina: multicenter study. Pregnancy Hypertension: An International Journal of Women's Cardiovascular Health 2012;2(3):188-9.

[16] Magee LA, Von Dadelszen P, Chan S, et al. The control of hypertension in pregnancy study pilot trial. BJOG: An International Journal of Obstetrics \& Gynaecology 2007;114(6):770, e13-20.

[17] Pollock W, Rose L, Dennis CL. Pregnant and postpartum admissions to the intensive care unit: a systematic review. Intensive Care Medicine 2010;36(9):1465-74.

[18] Jain M, Modi JN. An audit of obstetric admissions to intensive care unit in a medical college hospital of central India: lessons in preventing maternal morbidity and mortality. Int J Reprod Contraception Obstet Gynecol 2015;4(1):140-5.

[19] Zwart JJ, Dupuis JR, Richters A, et al. Obstetric intensive care unit admission: a 2-year nationwide population-based cohort study. Intensive Care Medicine 2010;36(2):256-63. 